\title{
A Contrastive Study of English and Chinese Book Reviews on Linguistics: Perspective of Attitudinal Meanings
}

\author{
Chunsong Cheng \\ Quzhou University, Quzhou, China
}

\begin{abstract}
The paper attempts to make a contrastive analysis of English and Chinese book reviews on linguistics in the light of the appraisal theory to discover the similarities and differences between English book reviews on linguistics (henceforth EBRLs) and Chinese book reviews on linguistics (henceforth CBRLs) with respect to the three attitude variables of affect, judgment and valuation. In both EBRLs and CBRLs, affect only takes up a very small part. Appreciation accounts for the great majority of attitude. Among all appreciation instances, positive valuations dominate positive appreciations, and negative compositions constitute the highest percentage of negative appreciations. In addition, EBRLs keep a higher percentage of reaction than CBRLs. Because reaction is more subjective than composition and valuation, it is concluded that English reviewers tend to take subjective ways more frequently than their Chinese counterparts to express their opinions. As for judgment, all the instances of judgment in the 40 book reviews are those of social esteem, especially of capacity. Chinese reviewers attend more to the author's background, such as his history, reputation and previous publications, etc., than their western counterparts who attach more importance to the efforts the author has made to the book.
\end{abstract}

Index Terms - book review, the appraisal theory, attitude, contrastive study

\section{INTRODUCTION}

A book review, in simple words, introduces and evaluates a book or books bearing upon a single subject or related subjects. It "describes and characterizes not only the book in question, but also the topic with which it is dealing" (Nicolaisen, 2002, p. 129). Thus, book reviews "can successfully be utilized to trace the flow of information within and across knowledge domains" (Lindholm-Romantschuk, 1998, p. viii) and support "both the manufacture of knowledge and the social cohesiveness of disciplinary communities" (Hyland, 2000, p. 43). They, as a result, could be regarded as important vehicles for scholars and scientists to keep up with the latest professional developments despite the continual growth and dissemination of recorded knowledge.

Since the 1970s, scholars have shown their constant interest in academic discourse, but before the middle 1980s, academic discourse studies were carried out from the perspectives of anthropology, psychology, sociology, etc., rather than from the perspective of linguistics. Since the late 1980s, linguistic approaches such as genre analysis (Swales, 1990), multi-dimensional analysis (Biber et al., 1988) and the perspective from systemic functional linguistics, among others, have been exploited in various attempts to analyze academic discourse (Jiang \& Zhao, 2006, p. 1). Since the middle 1990s, academic book reviews have been studied from the perspective of linguistics (such as Motta-Roth, 1995). Few attempts have been made to conduct English-Chinese contrastive analysis in this respect.

Book reviews are rich in evaluative resources, and hence they are evaluation-loaded by nature, especially, in comparison with all the other genres existing in the academy (Hyland, 2000). Evaluation is a central part of the meaning of any text. Any analysis of the interpersonal meaning of a text must take it into account (Thompson, 1996, p. 65). It performs three functions: to express opinions, to construct and maintain relationships, and to organize discourses (Thompson \& Hunston, 2000, p. 6). Identifying what speakers or writers think reveals the value system of these persons and their community. Evaluation in book reviews, as a result, is a topic worthy of study.

Evaluation is a concept that crosses discipline boundaries and has many diverse applications. Even within the field of linguistics, the term is used in different ways across a number of specialisms. In this paper, book reviews are studied in the light of the appraisal theory (Martin, 2000; Martin \& Rose, 2003; Martin \& White, 2005).

Appraisal refers to "the semantic resources used to negotiate emotions, judgment and valuations" (Martin, 2000, p. 145). It "includes gradable resources for evaluating people, places and things in our experience (attitude), for adjusting our commitment to what we evaluate (engagement) and for tuning up or down the volume of these (graduation)" (Macken-Horarik, 2003, p. 296). In view of the broad system of appraisal and limited space, the present study focuses on attitude, one type of specific appraisal resources.

For considerable disciplinary distinctions exist among book reviews across disciplines (Hyland, 2000; Suárez-Tejerina, 2005; Suárez-Tejerina \& Moreno, 2006), the book reviews examined in the study are restricted to those on linguistics, with which we are more familiar than those in other disciplines. What is more, the literature reveals 
that few studies focus on or are related to Chinese book reviews. On account of these facts, this thesis attempts to study attitudinal meanings and their realizations in English and Chinese linguistics book reviews in the light of the appraisal theory, the system of attitude in particular in order to explore similarities and differences between EBRLs and CBRLs in terms of attitude. The differences may reveal some genre-dependent and language-bound rhetorical preferences and some differences between western and Chinese cultures.

\section{AtTitudinal MeAnings}

Halliday $(1985 ; 1994 ; 2004)$ claims that language is structured to make three main kinds of meanings simultaneously. They are ideational, interpersonal and textual meanings. Interpersonal meaning is mainly achieved by means of mood and modality. However, there are some other potentials of linguistic units for realizing interpersonal meaning. Evaluation, among others, is another kind of linguistic resource to express interpersonal meaning. It expresses speakers' or writers' opinion, and in doing so to reflect the value system of these persons and their community; it constructs and maintains relations between addressers and addressees; it organizes the discourse (Thompson \& Hunston, 2000, p. 6). Halliday $(1985 ; 1994 ; 2004)$ argues that comment adjuncts and the attitudinal type of epithet express speakers' or writers' attitude, and express interpersonal meaning too. Butt (1994, p. 83) also mentions that comment adjuncts and attitudinal lexis can be used to express attitude.

The appraisal theory (Martin, 2000; White, 2001; Martin \& Rose, 2003; Martin \& White, 2005) provides us with an integrated framework to have a comprehensive study of interpersonal meaning and the construction of evaluative stance in texts. Appraisal is characterized by three evaluative resources: attitude, engagement and graduation. "Attitude is concerned with our feelings, including emotional reactions, judgments of behavior or character and evaluation of things" (Martin \& White, 2005, p. 35). Accordingly, attitudinal meanings refer to "speakers' or writers' emotional responses" or their view of the "social acceptability of the behavior of human actors" or their assessment of "semiotic and natural phenomena by reference to their value" (White, 2002, p. 5-6). According to the theory, resources for expressing feelings are technically referred to as affect, resources for judging behavior or character as judgment and resources for valuing the worth of things as appreciation.

Affect is concerned with resources for speakers or writers to indicate how they are emotionally disposed to the person, thing, happening or state of affairs (White, 2001, p. 8). Under affect, we are concerned with emotions, with positive and negative emotional responses and dispositions: do we feel happy or sad, confident or anxious, interested or bored? As such, affect may be classified into three major sets having to do with un/happiness, in/security and dis/satisfaction.

"Judgment is concerned with resources for assessing behavior according to various normative principles" (Martin \& White, 2005, p. 35). Under judgment, we criticize or praise, condemn or applaud the behavior - the actions, deeds, sayings, beliefs, motivations etc. — of human individuals and groups (White, 2001, p. 16). Judgment falls into two major groups: social esteem and social sanction. Social esteem which involves admiration and criticism has to do with normality (how unusual someone is), capacity (how capable they are) and tenacity (how resolute they are); social sanction which on the other hand involves praise, and condemnation has to do with veracity (how truthful someone is) and propriety (how ethical someone is) (Martin \& White, 2005, p. 52).

As for appreciation, we turn to meanings construing our evaluations of things, including the things we make, performances we give and natural phenomena - what such things are worth (how we value them) (Martin \& White, 2005, p. 56). Appreciation of things includes our attitudes towards natural phenomena and semiosis (as either product or process). It is organized around three variables - reaction, composition and valuation. Reaction has to do with the degree to which a thing in question captures our attention (reaction: impact) and the emotional impact it has on us (reaction: quality); composition has to do with our perceptions of proportionality (composition: balance) and detail (composition: complexity) in the thing; valuation has to do with our assessment of the social significance of the thing in question (Martin \& Rose, 2003, p. 55-56).

Instantiations of appraisal can be explicit (inscribed) or implicit (evoked as tokens). Under the inscribed category, the evaluation is often explicitly presented by means of a lexical item carrying attitudinal value, thus, "happy", "beautiful", "wonderful", etc. Under the evoked category, attitudinal values are achieved by lexical enrichment of some kind over one or more spans of text and triggered by what can be viewed as simply "facts", apparently unevaluated descriptions of some event or state of affairs. Readers can infer the attitudinal meanings from the descriptions.

\section{RESEARCH METHODOLOGY}

Miranda (1996) puts forward the key features of successful reviews, among which are identifying the strengths and weakness of the arguments and evaluating the contribution of the text. Consequently, the so-called reviews which provide only a general view of the book rather than an actual evaluation are not included in the present study. The study is based on a corpus of 40 linguistics book reviews: 20 in English and 20 in Chinese. The 20 English book reviews are drawn from 3 English linguistics journals: Language (published by the Linguistic Society of America), Journal of Linguistics (the journal of the linguistics Association of Great Britain), and Applied Linguistics (published in cooperation with American Association for Applied Linguistics, International Association of Applied Linguistics and 
British Association for Applied Linguistics). Likewise, the 20 Chinese ones are taken from Foreign Language Teaching and Research (published by Beijing Foreign Studies University), Modern Foreign Languages (published by Guangdong University of Foreign Studies) and Contemporary Linguistics (published by the Institute of Linguistics under the Chinese Academy of Social Sciences). All these academic journals are among the most prestigious and representative ones in the field of linguistics either abroad or at home. All the EBRLs for study are written by native English speakers in western countries, and CBRLs by native Chinese speakers.

As for the research method, quantitative and qualitative approaches which are complementary to each other will be adopted in the study. The quantitative approach serves to calculate attitudinal resource occurrences to produce comparable data in both EBRLs and CBRLs, while the qualitative approach is employed to decide whether the similarities and differences are significant or not. The study will be carried out at the following three stages.

At the first stage, all the complete texts are read and analyzed with the purpose of identifying all the instances of attitude within the texts. The identification is conducted manually.

The second stage involves classifying these instances of attitude according to different criteria, e.g. positive and negative attitudes, explicit and implicit expressions etc. and processing quantitative data for the two groups of texts. In addition, a parallel comparison of the quantitative results will be included at this stage.

At the third stage, similarities and differences between the two groups of texts with respect to attitudinal meanings will be sorted out. The chi-square test $\left(\mathrm{x}^{2}\right)$ is used on the frequency data so as to test whether the differences are statistically significant or not. Then, the similarities and differences will be interpreted in terms of context and characteristics of book reviews.

\section{FINDINGS AND DISCUSSIONS}

After identifying and analyzing, we find that instances of attitude, positive or negative, intersperse throughout different parts of EBRLs and CBRLs.

\section{A. General Tendency of Sub-types of Attitude}

Attitude falls into three categories: affect, judgment, and appreciation. Each of them has different performance in the book reviews of the two languages. Table I presents the total numbers and percentages for each of the three categories.

TABLE I

SUB-TYPES OF ATTITUDE IN EBRLS AND CBRLS

\begin{tabular}{|c|c|c|c|c|c|c|}
\hline \multirow{2}{*}{ Review } & \multicolumn{2}{|l|}{ Affect } & \multicolumn{2}{|c|}{ Judgment } & \multicolumn{2}{|c|}{ Appreciation } \\
\hline & Number & Percentage & Number & Percentage & Number & Percentage \\
\hline EBRL & 19 & $3.3 \%$ & 92 & $16.1 \%$ & 462 & $80.6 \%$ \\
\hline CBRL & 6 & $1.0 \%$ & 100 & $17.2 \%$ & 477 & $81.8 \%$ \\
\hline
\end{tabular}

As the table shows, there are few instances of affect in both of EBRLs and CBRLs. In EBRLs, there are 19 instances of affect and they take up only 3.3\% of the total attitudinal items. In CBRLs, there are fewer instances of such variable (6 instances), and their proportion is only $1.0 \%$.

Book reviews are a type of academic discourse in the sense that they evaluate books from the academic perspective and are like research papers in some ways (Xu, 1993, p. 80). As such, book reviews have to be "scientific and objective" (Markkanen \& Schroder, 1997, p. 12). However, affect, as indicated above, is modeled as a semantic resource for construing emotions. It is subjective. Frequent use of affectual positioning may make the text personalized and make the reviewer's point of view less convincing. Therefore, in book reviews, affectual positioning is seldom used to express the reviewer's attitude. On average, English book reviews keep a higher proportion of affect than Chinese ones (3.3\% for EBRLs as compared with $1.0 \%$ for CBRLs), but a chi-square test conducted on the data shows that EBRLs and CBRLs are statistically significant in terms of affect $\left(\mathrm{x}^{2}=8.89, \mathrm{df}=1, \mathrm{p}<0.01\right)$.

As to judgment, in the 20 EBRLs, there are 92 instances of judgment which make up $16.1 \%$ of the total attitude instances; in CBRLs, there are 100 instances of judgment which constitute $17.2 \%$ of the total attitude instances. In this respect, EBRLs and CBRLs are alike $\left(\mathrm{x}^{2}=0.27, \mathrm{df}=1, \mathrm{p}>0.01\right)$. As we know, the quality of a book is related to, or determined by, to some extent, the author's efforts and performance. Sometimes, reviewers evaluate a book by appraising the author's performance. On the other hand, judgment deals with human behavior, which is not the emphasis of book reviews. Thus it is reasonable that there are a certain number of judgment instances, but they only constitute a small part of the total instances of attitude.

Both EBRLs and CBRLs foreground appreciation. In EBRLs, out of 563 cases of attitude, $80.6 \%$ of them are appreciations; in CBRLs, out of 583 instances of instances, $81.8 \%$ of them are appreciations. A chi-square test conducted on the data shows that EBRLs and CBRLs are remarkably close to each other in this respect $\left(\mathrm{x}^{2}=0.005, \mathrm{df}=1\right.$, $\mathrm{p}>0.01)$. Appreciation accounts for the great majority of attitude items. This phenomenon arises due to the characteristics of book reviews.

Appreciation is modeled as a semantic resource for construing our evaluations of things. Book reviews are concerned with books, so reviewers put greater emphasis on appreciation than affect or judgment. Appreciation can be expressed from various perspectives. Composition has to do with the language, coverage, structure or organization of the book. 
Valuation deals with the significance and importance of the book, or of the study the book focuses on. "Intriguing" and "interesting" are often used to express reaction. Judgment and appreciation in book reviews on linguistics will be discussed in the following sections.

\section{B. Judgment}

As discussed above, judgment falls into two categories: social esteem and social sanction. Social esteem has to do with normality, capacity and tenacity; social sanction has to do with veracity and propriety. In both EBRLs and CBRLs, all the judgments made by reviewers belong to the category of social esteem. This means that they appraise the author in terms of normality, capacity and tenacity. In most cases, the author's capacity is appraised. For example,

(1) She succeeds in resuscitating "Grassmann's important demonstration of the fundamental accusative identity of these forms", showing, that is, that they function as pronominals even in the Rigveda. ${ }^{1}$

(2) 作者 Maeve Olohan 是英国曼切斯特大学翻译与跨文化中心的高级讲师, 曾与Mona Baker一起创建了世界 上第一个翻译语料库, 在翻译语料库研究方面颇有建树。2

In these examples, the boldfaced parts are inscribed instances of judgment which indicate the authors are capable. The italicized part in (2) also implies that the author is capable, but it is an instance of implicit capacity. All the instances in (1) and (2) are judgments of social esteem as opposed to judgments of social sanction that might carry ethical or legal weight and be used to make judgments about morals. Reviewers in the study present no evidence of the latter kind of persuasive opinions. This might be seen as related to the field and characteristics of book reviews. EBRLs and CBRLs share a common field. They are academic discourse, and serve to introduce and evaluate books on linguistics positively or negatively from the academic perspective. Academic issues are discussed in book reviews. The quality of books is mainly related to authors' capacity and tenacity instead of veracity or propriety.

Table II below tabulates the numbers and percentages for positive and negative judgments in EBRLs and CBRLs.

TABLE II

POSITIVE AND NEGATIVE JUDGMENT IN EBRLS AND CBRLS

\begin{tabular}{|c|c|c|c|c|}
\hline \multirow{2}{*}{$\overbrace{\text { Review }}$ Judgment } & \multicolumn{2}{|l|}{ Positive } & \multicolumn{2}{|l|}{ Negative } \\
\hline & Number & Percentage & Number & Percentage \\
\hline EBRL & 68 & $73.9 \%$ & 24 & $26.1 \%$ \\
\hline$\overline{\text { CBRL }}$ & 84 & $84.0 \%$ & 16 & $16.0 \%$ \\
\hline
\end{tabular}

In EBRLs, the negative judgments amount to $26.1 \%$ of the total judgments; in CBRLs, the negative judgments take up only $16.0 \%$ of the total judgments. The percentage of negative judgments ( $26.1 \%$ in English and $16 \%$ in Chinese) is lower than that of negative appreciations in all appreciations in either EBRLs (40.3\%) or CBRLs (21.2\%). These statistics indicate that reviewers criticize the book with preference to the author.

In book reviews, the author is involved. His behavior is appraised. At the same time, he perhaps is a reader. Judgment which is made more directly to the author than affect or appreciation which is made directly to the book can be seen to hold much higher interpersonal stakes than affect or appreciation. Negative judgment, in particular, causes damage to the author of the book in question as it can undermine his academic reputation, credibility and the solidarity between the reviewer and the author more seriously and directly. For example,

(3) Anthonissen (p. 95) writes of the three metafunctions which discourse performs often simultaneous. Often? It is hard to imagine any text without the simultaneous presence of ideational, interpersonal, and textual meanings; surely that is the point of the Hallidayan metafunctions? ${ }^{3}$

(4) 作者并没有在书的哪个部分严格地总结出男性语言的特点和男子气概的定义, 所以在许多分析中让人觉 得有些随意。 4

In (3), there is no inscribed attitudinal lexis used to criticize the author, but the italicized part, especially the two question marks and "hard", implies the reviewer's criticism towards the author for his incapacity or ignorance. According to the reviewer, the author should have known the basic point of systemic functional linguistics very well. Such a negative judgment, though it is evoked, carries more interpersonal implications for the author than negative affect or appreciation which is made to the book and mitigates the criticism to the author. Negative judgment is more likely to elicit interpersonal conflict and undermine the solidarity between the reviewer and the author seriously.

The boldfaced word in (4) is an explicit instance of negative judgment, which is a serious criticism to the author's behavior. The italicized part in (4) is also an instance of negative judgment. Though implicit, they are made directly to the authors' behavior, and more likely to elicit interpersonal conflict. Thus it is reasonable that the proportion of negative judgments to all judgments is lower than that of negative appreciations to all appreciations in both EBRLs and CBRLs.

\footnotetext{
1 Joseph, B. D. (2006). Review of Indian Linguistic Studies: Festchrift in Honor of George Cardona edited by M. Madhav, Deshpande, \& Peter E. Hook. Language 83. 4, 902-904.

${ }^{2}$ Huang, Qin (2007). Review of Introducing Corpora in Translation Studies by M. Olohan. Contemporary Linguistics 9. 1, 87-91.

${ }^{3}$ Baynham, M. (2006). Review of Re/reading the Past: Critical and Functional Perspectives on Time and Value by J. R. Martin and Ruth Wodak. Applied Linguistics 27. 2, 331-334.

${ }^{4}$ Wu, Yayin. (2006). Review of Men Talk: Stories in the Making of Masculinities by Jennifer Coates. ContemporaryLinguistics 8. 3 , $272-277$.
} 
So far, the similarities between EBRLs and CBRLs in terms of judgment have been discussed. According to Table II, it seems that no significant differences exist. However, a deeper investigation of the instances of judgment reveals that it is not the case.

In book reviews, there is a step which introduces the author. It provides the information about the author, such as his experience, previous publications and so on. Meanwhile, the reviewer appraises the author's behavior in the step. The study finds that only 3 out of the 20 EBRLs provide such information and only 9 instances of judgment (accounting for 9.8\% of all instances of judgment) inform about the author in EBRLs. The great majority of judgments appraise the author's efforts he has made to the book. In contrast, 10 out of the 20 CBRLs provide such information and 27 instances (accounting for $27 \%$ of all instances of judgment) appear in CBRLs. These statistics might be interpreted in stereotypical terms as that Chinese reviewers attend more to the author's academic title, reputation and previous publications than English reviewers. This phenomenon might be related to the different cognitive styles of field-dependence (FD) and field-independence (FI).

According to Witkin et al. (1977), the FI /FD dimensions are defined as "the extent to which a person perceives part of a field as discrete from the surrounding field as a whole, rather than embedded in the field and the extent to which a person perceives analytically" (p. 7). A field-independent person has an analytic view focusing on salient objects and their attributes, while a field-dependent person has a holistic view that takes into account the context and relationships involved (Nisbett, 2003, p. 82).

Usually, East Asians are more field-dependent. They pay more attention to background than westerners. Instead, westerners are more field-independent. They are more likely to separate the object from its environment, and attach more importance to objects themselves (Nisbett, 2003). As to judgment in book reviews, Chinese reviewers pay more attention to the background of the author, i.e. academic title, reputation and previous publications, than English reviewers. According to them, there is an important relationship between the author's academic title, reputation and previous publications and the success of the book under review. English reviewers put more emphasis on the author's efforts which he has made to the book. They tend to attribute the success of the book to the efforts the author has made. For instance,

(5) Her insistence on the interdisciplinary nature of the enterprise is fully warranted and, to some extent, borne out in the chapters that follow. ${ }^{5}$

(6) John Sinclair, 英国著名语言学家, 出版著作 30 多本, 发表文章上百篇, 在话语分析和语料库语言学两个 领域成绩显著。6

In (5), the author is praised for her insistence. Instead, example (6) experiences a different phenomenon. It introduces the authors' background, i.e. their academic records, professional titles and reputation. The boldfaced and italicized parts, certainly, are instances of judgment. In addition, the expression in bold face in (2) is an instance of judgment too. All of them provide the readers with some information of the authors' background.

Chinese reviewers attend more not only to the background of the author, but also to the background of the study to which the book relates. They introduce the background of the study and insert the study into the broad field. Among the 20 Chinese book reviews, 11 have an introduction of the background of the study. In contrast, only 4 out of the 20 English book reviews introduce such study background.

\section{Appreciation}

The system of appreciation is organized around three variables: reaction, composition and valuation. In order to gain a clear picture of the configurations of appreciation, we study these variables of appreciation from two perspectives: positive and negative perspectives.

\section{Positive Appreciation}

Table III tabulates realizations of positive appreciation variables of reaction, composition, and valuation.

TABLE III

VARIABLES OF POSITIVE APPRECIATION IN EBRLS AND CBRLS

\begin{tabular}{|l|l|l|l|l|l|l|}
\hline \multirow{2}{*}{ Review Appreciation } & \multicolumn{4}{|l|}{ Reaction } & Composition & Valuation \\
\cline { 2 - 7 } & Number & Percentage & Number & Percentage & Number & Percentage \\
\hline EBRL & 66 & $23.9 \%$ & 52 & $18.8 \%$ & 158 & $57.2 \%$ \\
\hline CBRL & 22 & $5.9 \%$ & 100 & $26.6 \%$ & 254 & $67.5 \%$ \\
\hline
\end{tabular}

In EBRLs, there are 158 occurrences of positive valuation, making up 57.2\% of the total positive appreciations in the corpus. In CBRLs, there are 254 cases of such type, comprising $67.5 \%$ of the total positive appreciations. These statistics suggest that positive valuation is dominant in positive appreciations. Reviewers often appraise the valuation of book reviews positively from many perspectives, such as research results, research methods, data, significance, implication and so on. For example,

(7) Any knowledgeable reader can see that his paper are full of new insights and provide data on which others can build. $^{7}$

\footnotetext{
${ }^{5}$ Bickerton, D. (2007). Review of Language Origins: Perspectives on Evolution edited by Maggie Tallerman. Journal of Linguistics 43. 1, 259-264

${ }^{6}$ Huang, Ruihong. (2007). Review of Trust the Text: Languag, Corpus and Discourse by John Sinclair. Modern Foreign Languages 30. 1, 102-104. 
(8) 本书的最大价值在于给语用学提供了许多新的启示, 开启了新的研究领域。8

In (7), the reviewer praises the book for its value in terms of research result and data respectively by means of "new" and "provide". Similarly, in (8), the author appraises positively the value and significance of the research result by the boldfaced words 价值(value), 提供(provide), 新(new) and 开启(start).

There are fewer instances of positive composition than positive valuation in the book reviews on linguistics. Compositions take $18.8 \%$ of the total positive appreciations in EBRLs; in CBRLs their percentage is about 26.6\%. What is more, one important purpose of book reviews is to promote the book. Positive valuation of the book is certainly the most important to potential readers. In addition, the reviewer appraises positively the composition of the book from fewer perspectives than they do on positive valuation. Usually, they express their attitude towards composition in terms of organization, structure and language. Examples of this kind include:

(9) The presentation is always lucid and there are ample illustrations that can be discussed in class. ${ }^{9}$

(10) 本书回顾了西方幽默研究理论和方法, 着重从语义学、句法学、语用学、语篇分析等角度分析了笑话的 语言结构、语篇特征、生成和理解的心理机制及计算机处理，例证丰富，可读性很强。 ${ }^{10}$

In (9), "lucid" means the points are expressed clearly, and "ample" is used to praise the book in that there are enough illustrations and the conclusion is convincing. In (10), “例证丰富” means that there are enough examples, and “可读性 很强” is an instance appraising the language. It means the book is easy to understand.

As to positive reaction, English reviewers tend to make more positive appraisals on reaction than Chinese reviewers. As Table III reveals, positive reactions make up $23.9 \%$ of all the positive appreciations in EBRLs, but the percentage of positive reaction in CBRLs is only $5.9 \%$. They are sharply different $\left(\mathrm{x}^{2}=51.37, \mathrm{df}=1, \mathrm{p}<0.01\right)$.

\section{Negative Appreciation}

As to negative appreciation, the situation is a little different. Table IV presents the number and percentage for each type of negative appreciation.

TABLE IV

VARIABLES OF NEGATIVE APPRECIATION IN EBRLS AND CBRLS

\begin{tabular}{|l|l|l|l|l|l|l|}
\hline \multirow{2}{*}{ Review } & Cppreciation & Reaction & Composition & \multicolumn{2}{l|}{ Valuation } \\
\cline { 2 - 7 } & Number & Percentage & Number & Percentage & Number & Percentage \\
\hline EBRL & 32 & $17.2 \%$ & 89 & $47.8 \%$ & 65 & $34.9 \%$ \\
\hline CBRL & 4 & $4.0 \%$ & 58 & $57.4 \%$ & 39 & $38.6 \%$ \\
\hline
\end{tabular}

In EBRLs, $47.8 \%$ of negative appreciations are instances of composition, and $34.9 \%$ of them are instances of valuation. These statistics mean that in negative appreciations, compositions account for the highest percentage in EBRLs. Much the same can be said for the analysis of negative appreciation in CBRLs, in which the percentage of negative compositions is $57.4 \%$, and that of negative valuations is $38.6 \%$.

The perspectives from which they make negative and positive composition are different. Reviewers usually point out explicitly or implicitly the incompletion of the book under review. They may point out what should be added. Examples of negative composition include:

(11) A number of the texts need more interpretation (such as the ICQ dialogue, pp. 218ff.). ${ }^{11}$

(12) 其次, 书中没有提及转喻在认知中的重要作用。12

These two examples are instances of implicit composition. Each of them criticizes the book for its incompletion. All these examples suggest that some more interpretation or materials should be added.

As far as negative valuation is concerned, EBRLs and CBRLs contain the similar percentage of the total negative appreciations $\left(34.9 \%\right.$ and $38.6 \%$ respectively). They are statistically of no difference $\left(x^{2}=0.75, \mathrm{df}=1, \mathrm{p}>0.01\right)$. The following examples are instances of negative valuation.

(13) I consider this to be a limitation of the book since, at least in principle, the interaction could be profitable in both directions. ${ }^{13}$

(14) 尽管该书在强调词汇的重要意义、连接二语习得研究与词汇教学等方面体现了显著的特点, 但也存在不 足之处。如部分章节有前后重复引用前人的研究以作论证的现象。14

\footnotetext{
${ }^{7}$ Ladefoged, P. (2007). Review of Speech Acoustic and Phonetics: Selected Writing by Gunnar Fant. Language 84. 1, 189-191.

${ }^{8}$ Du, Shihong. (2006). Context as Other Minds: The Pragmatics of Sociality, Cognition and Communication by Talmy Givon. Foreign Language Teaching and Research 38. 5, 316-318.

9 Jucker, A. H. 2007. Review of Regularity in Semantic Change by Elizabeth Closs Traugott and Richard B. Dasher. Journal of Linguistics 43. 1, 264-267.

${ }^{10}$ Liu, Chengyu \& Yingying, Li. (2006). Review of The Linguistics Analysis of Jokes by G. Ritchie. Contemporary Linguistics 8. 3 , $278-283$.

11 Gupta, A. F. (2006). Review of Chinese Englishes: A Sociolinguistic History by Kingsley Bolton. Applied Linguistics 27. 1, $145-147$.

12 Yu, Jianliang. (2006). Review of A Study of Cognitive Metaphor by Zhuanglin Hu. Modern Foreign Languages 29. 2, 206-209.

${ }^{13}$ Cecchetto, C. (2007). Review of Universal Grammar in the Reconstruction of Ancient Languages edited by Katalin E. Kiss. Journal of Linguistics 43. 1, 240-244.

${ }^{14} \mathrm{Li}$, Qinshen. (2006). Review of Vocabulary Myths: Applying Second Language Research to Classroom Teaching by Keith S. Folse. Foreign Language Teaching and Research 38. 6, 472-474.
} 
All the boldfaced parts here are explicit instances of negative valuation, and the italicized parts are implicit ones. Reviewers appraise the valuation of the book negatively from the same perspective as they do positively. In (14), 不足 之处 means limitation.

It is interesting to note that positive valuation constitutes the highest percentage of positive appreciation, and negative composition accounts for the highest percentage of negative appreciation. That is to say, as for positive appreciation, valuation of the book in question is stressed; as for negative composition, shortcomings in language and structure receive the most attention.

Usually, when introducing a book to others, we assume it is valuable; we hardly introduce a book for its good organization or structure alone. The value of the book under review takes precedence over its structure or organization. If we attend too much to negative valuation, the reader may doubt that the book is valuable. Therefore, when praising a book, we usually make its value prominent; when criticizing a book, we pay much more attention to the shortcomings in composition. Moreover, such shortcomings and limitations are easy to be mended, and negative compositions are also suggestions for improvement when the book is republished.

As for negative reaction, it constitutes $17.2 \%$ of the total in EBRLs, but it takes only about $4.0 \%$ of all the negative appreciations in CBRLs. They are significantly different too $\left(\mathrm{x}^{2}=9.94, \mathrm{df}=1, \mathrm{p}<0.01\right)$. From Table III, we learn that the percentage of positive reaction in EBRLs is higher than that in CBRLs. All these confirm that English reviewers keep a higher percentage of reactions. Examples of positive and negative reaction in EBRLs include:

(15) Moreover, the paper by Peter Hook and Kusum Jain offers some intriguing facts about how sarcasm is achieved in Hindi-Urdu, providing as well a typology of different kinds of sarcasm. ${ }^{15}$

(16) From my overview of PPL so far, the title of the book might seem puzzling. ${ }^{16}$

In the two examples, "intriguing" is an instance of positive reaction, and "puzzling" is one of negative reaction. According to our study, positive reaction, in most cases, is expressed by means of "intriguing", "interesting" in EBRLs.

Table I confirms that EBRLs make more frequent use of affect though the difference is not significant. In this section, we conclude that EBRLs keep a higher percentage of reaction, positive or negative, than CBRLs. We think they are caused by the same reason.

As illustrated above, affect is personalized and subjective. Appreciation reworks feelings as propositions. It describes the writer's or speaker's feelings through a comparatively objective way. However, among the three variables of appreciation, "reaction is the least differentiated from affect" (Painter, 2003, p. 205) and is more subjective than composition and valuation. In book reviews, reviewers express their personal views towards the book; as such their views are subjective in nature. However subjectivity in academic discourse is often avoided in order to achieve objectivity, for book reviews are a kind of academic discourse. From these propositions, it follows that English reviewers tend to take subjective ways more frequently than Chinese ones to express their opinions, and Chinese reviewers are more likely to take objective ways in order to achieve objectivity.

\section{CONCLUSIONS}

In both EBRLs and CBRLs, affect only takes up a very small part among all the instances of attitude because it is personalized and subjective. Appreciation accounts for the great majority of attitude. Positive valuations dominate positive appreciations, and negative compositions constitute the highest percentage of negative appreciations. Usually, when introducing a book to others, we assume it is valuable; generally we do not introduce it just for its good organization or structure. Therefore, when praising a book, we generally make its value prominent. Instead, when criticizing a book, we attend much more to the shortcomings and limitations in composition. If we attend too much to negative valuation, the reader may doubt that the book is valuable. EBRLs keep a higher percentage of affect and reaction, positive or negative, than CBRLs. Affect is personalized and subjective. Among the three variables of appreciation, reaction is more subjective than composition and valuation. There are more instances of reaction in EBRLs than in CBRLs. Therefore, we conclude that English reviewers tend to take subjective ways more frequently than Chinese ones to express their opinions, and Chinese reviewers are more likely to take objective ways in order to achieve objectivity.

On the other hand, books are written or edited by human beings; sometimes, the author is appraised in book reviews. So there are some instances of judgment in book reviews but they are not dominant in all the instances of attitude. Appreciation accounts for the great majority of attitude. All the instances of judgment in the 40 book reviews are those of social esteem, especially of capacity. In addition, authors are involved in judgment, and as such judgment bears higher interpersonal stakes than affect or appreciation. Therefore, the percentage of negative judgment is lower than that of negative attitudes in all attitudes and that of negative appreciations in all appreciations in either EBRLs or CBRLs. What is more, Chinese reviewers attend more to the author's background, such as his history, reputation and previous publications, etc., than their western counterparts who attach more importance to the efforts the author has made to the

\footnotetext{
15 Van Valin, R. D. (2007). Review of Constructions at Work: The Nature of Generalization in language by Adele E. Goldberg. Journal of Linguistics 43. 1, 234-239.

${ }^{16}$ Dryer, M. S. (2007). Review of Possible and Probable Languages: A Generative Perspective on Lingusitic Typology by Frederick J. Newmeyer. Journal of Linguistics 43. 1, 244-251.
} 
book. This is because Chinese are more field-dependent, and give more attention to background; westerners are more likely to separate the object from its environment and attend more to the object itself.

\section{REFERENCES}

[1] Biber, D. et al. (2002). Speech and writing in the university: A multidimensional comparison. TESOL Quarterly 36. 1, 9-48.

[2] Halliday, M. A. K. (1985). An introduction to functional grammar. London: Edward Arnold.

[3] Halliday, M. A. K. (1994). An introduction to functional grammar (2nd edn.). London: Edward Arnold.

[4] Halliday, M. A. K. (2004). (Revised by Christian M. I. M. Matthiessen). An introduction to functional grammar (3rd edn.).London: Edward Arnold.

[5] Hyland, K. (2000). Disciplinary discourses: Social interactions in academic writing. London: Longman.

[6] Jiang, Yajun \& Gang Zhao. (2006). Linguistic approaches to academic discourse: Division and integration. Foreign Languages Research. 23, 6: 1-5.

[7] Lindholm-Romantschuk, Y. (1998). Scholarly book reviewing in the social sciences and humanities: The flow of ideas within and amongst disciplines. Westport, CT: Greenwood Press.

[8] Macken-Horarik, M. (2003). Appraisal and the special instructiveness of narrative. Text 23. 2, 285-312.

[9] Martin, J. R. (2000). Beyond exchange: Appraisal systems in English. In S. Hunston \& G. Thompson (eds.), Evaluation in Text. Oxford: Oxford University Press, 142-175.

[10] Martin, J. R. \& D. Rose (2003). Working with discourse: Meaning beyond the clause. New York: Continuum.

[11] Martin, J. R. \& P. R. R. White (2005). Language of evaluation: Appraisal in English. New York: Palgrave.

[12] Miranda, E. O. (1996). On Book Reviewing. Journal of Educational Thought 30. 2, 191-202.

[13] Motta-Roth, D. (1995). Book Reviews and Disciplinary Discourses: Defining a Genre. Paper Presented at the TESOL 29th Annual Convention \& Exposition. Long Beach, CA, USA. http://www.ufsm.br/labler/publi/book.htm (accessed 5/4/2013).

[14] Nicolaisen, J. (2002). The Scholarliness of published peer reviews: A bibliometric study of book reviews in selected social science fields. Research Evaluation 11. 3, 129-140.

[15] Nisbett, R. E. (2003). The geography of thought: How Asians and Westerners think differently ... and why. New York: The Free Press.

[16] Painter, C. (2003). Developing attitude: An ontogenetic perspective on appraisal. Text 23. 2, 183-209.

[17] Suárez-Tejerina L. (2005). Is evaluation structure-bound? An English-Spanish contrastive study of book reviews. In E. Tognini-Boneli \& C. Del Lungo (eds.), Strategies in academic discourse. Philadelphia: John Benjamins Publishing Company, $117-132$.

[18] Suárez-Tejerina L. \& A. I. Moreno. (2006). The rhetorical structure of academic journal book reviews: A cross-linguistic and cross-disciplinary approach. http://www.unizar.es/aelfe2006/ALEFE06/1.discourse/28..pdf (accessed 5/4/2012).

[19] Swales, J. M. (1990). Genre analysis: English in academic and research settings. Cambridge: Cambridge University Press.

[20] Thompson, G. (1996). Introducing functional grammar. London: Edward Arnold.

[21] Thompson, G. \& S. Hunston. (2000). Evaluation: An introduction. In S. Hunston \& G. Thompson (eds.), Evaluation in text. Oxford: Oxford University Press, 1-27.

[22] White, P. R. R. (2001). Appraisal: An overview. http://www.grammatics.com/appraisal/AppraisalGuide/Appraisal Guide WPFiles. html (accessed 5/4/2007).

[23] White, P. R. R. (2002). Appraisal. http://www.benjamins.nl/online/hop (accessed 9/4/2012).

[24] Witkin, H. A. et al. (1977). Field dependent and field independent cognitive styles and their educational implications. Review of Educational Research 47. 1, 1-64.

[25] Xu, Bairong (1993). A study of book reviews. Harbin: Heilongjiang Education Press.

Chunsong Cheng is a lecturer at Quzhou University, Zhejiang Province, China. He has a B.A. in English teaching from Zhejiang Normal University and an M.A. in Linguistics from Ningbo University. His research interests include functional linguistics and English teaching. 